\title{
Heredia y el enigma de "Los últimos romanos"
}

Ja producción dramática de José María Heredia aún plantea un problema a los investigadores, con la tragedia Los últimos romanos. ¿Es ésta una obra original, o es traducción o imitación de una obra extranjera, posiblemente francesa? Hacia esta última opinión se han inclinado algunos críticos, basándose en el hecho de que Heredia cuidó de poner, en el plan de su tragedia proyectada en la juventud Xicotencal o los tlascaltecas, la palabra "original", y no hizo lo mismo en los casos de otras obras de procedencia dudosa o definida más tarde.

"En El campesino espantado, Eduardo IV o el usurpador Clemente, Los últimos romanos, Sila, Tiberio -hace notar Francisco González del Valle-, no expresa Heredia que eran originales suyas, ni tampoco de qué autores toma el asunto. Deben pues tenerse por imitadas o arregladas dichas obras, de otros autores". (Cronología herediana, p. 128 .)

Don Marcelino Menéndez y Pelayo, que fué el primero en advertir de quién tradujo Sila, no conoció la última tragedia que Heredia publicó. Cautamente declara, en la Historia de la poesía hispano-americana: "De otra tragedia, al parecer original, Los últimos romanos, no conocemos más que el título". La opinión del gran erudito, pierde así toda la fuerza que pudiera 
tener, sin la frase final, que nos impide tomarla como una afirmación de que es original dicha obra.

Quienes se han inclinado a creer que se trata efectivamente de una obra original de Heredia, se apoyan en lo expresado por Francisco Pi y Margall, en su Historia de España en el siglo $X I X$ (t. III, p. 55I), donde dice, refiriéndose a las tragedias: "Tradujo otras muchas y escribió una original, titulada Los Ultimos Romanos".

El historiador cubano Pedro José Guiteras, que trazó la biografía de Heredia, dijo acerca de Los últimos romanos: "No sabemos si es original suya o una traducción. Su asunto está tomado de aquella época aciaga, en que la corrompida república romana sucumbió con la muerte de Bruto en los campos de Filipos. La forma de esta tragedia es de la mejor escuela clásica, y el noble carácter del protagonista está realizado con toda la elevación de sentimientos con que lo ha trasmitido la historia a la posteridad; y debe sentirse que el último acto no corresponda con los dos primeros en las proporciones de sus partes. De todas sus composiciones dramáticas ésta es la que más contentó el gusto del autor por la fuerza de las ideas y la valentía del estilo".

González del Valle, en la introducción de la Cronología, al hablar acerca de los papeles del archivo de Figarola-Caneda, dice: "Pero esto no ha venido a nosotros por haber sido donado a la biblioteca de Versalles, según nos lo ha comunicado el señor $\mathrm{L}$. Boxhorn, residente en París.

"Después de largas y pacientes pesquisas logró averiguar Figarola, según nos lo asegura el doctor Francisco de Paula Coronado, que la tragedia Los últimos romanos, de Heredia, era traducción de una obra de autor francés, de la que poseía un ejemplar Figarola, que presumimos se encuentre entre los libros donados a la biblioteca de Versalles, citada"... (Cronologia herediana, p. 7). 


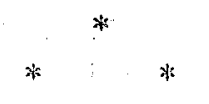

Mientras no se conozca el resultado de las "largas y pacientes pesquisas" de Figarola y se publiquen el nombre del autor y el título de la obra francesa, de la cual -según el doctor Francisco de Paula Coronado-, es traducción la tragedia Los últimos romanos, tan aventurado es afirmar esto como lo contrario: que se trata de una obra original.

Nos lleva insensiblemente hacia aquella opinión el hecho de que el poeta cubano haya preferido, las más de las veces, traducir en vez de hacer obra original, para el teatro.

No obstante, algo nos detiene y nos obliga a comunicar aquí la incertidumbre, que tal vez una revelación -hace tiempo esperada - pueda disipar, tarde o temprano.

La duda personal de quien esto escribe, se debe a las circunstancias en que iba a estrenarse la tragedia Los últimos romanos; a la advertencia que apareció al frente de la tragedia, cuando se publicó ésta en "La Miscelánea" (Tlálpam, I829), y a la obra misma.

Como se recordará, "aceptada ya gustosamente por los actores", el autor la retiró al saber que "algunas personas habían prevenido a las autoridades", por suponer que había en la "obra alusiones malignas". Ante las gratuitas e infundadas suposiciones, Heredia se limita a decir que esas mismas personas "se hubiesen reído" de su empeño, "a saber el tiempo en que se escribió".

Si bien es cierto que con esta últina frase enigmática lo mismo puede referirse a otra época -o situación política initernaque a tiempos pasados $y$, por consiguiente, a un autor no contemporáneo, que pudo haberle servido de modelo en su trabajo - de no ser éste original-, más sencillo habría sido, para Heredia, escribir: "a saber de quién es la obra que traduje", o bien “a saber que fué escrita en francés, por tal autor", y que, por consiguiente, en nada podía aludir a una situación mexicana pos. 
terior a su factura. Esta sería la actitud de cualquier traductor.

Heredia adoptó una actitud decorosa y prudente, pues el 24 de julio de ese año ( 1829 ) había sido nombrado capitán de la Compañía de Nacionales de Artillería, en Tlálpam.

Probablemente el dramaturgo prefirió sacrificar el deseo de ver representada la tragedia, ante la posibilidad de que las "autoridades superiores" llegaran a creer que en ella había "alusiones malignàs”. Ajeno a la intención malévola que le atribuian, Hèredia se contentó, pues, con publicar Los últimos romanos, y esto se hizo precisamente en la Imprenta del Gobierno, como demostración de que no había el menor fundamento para la intriga tramada en torno de otra intriga: la de su tragedia personal, de que habla en la dedicatoria de la obra.

Además, en la misma "Advertencia del Atitor" que precede a Los últimos romanos, en "La Miscelánea", aquél dice que "la publica hoy, porque desea inculcar a los jóvenes que se dedican a este ramo, la sencillez de acción y severidad de estilo que se propuso emplear si es que logró conseguirlo".

Habla pues como autor y no como traductor. Al concluir la advertencia, cuando se refiere a "algunas expresiones fuertes que podrían alarmar a conciencias delicadas", hace notar que los personajes "son gentiles y sectarios de la filosofía estoica; así el autor no pudo hacerlos hablar conforme a los principios de la augusta moral cristiana, sin incurrir en grave torpeza".

Todas estas palabras suenan más bien como aclaraciones de autor, que como disculpas o justificaciones de traductor.

En ningún caso se advierte la dualidad que hubiera dado lugar a distingos, si el autor - Heredia, en este caso- fuera sólo el traductor y tratara de deslindar los respectivos campos y las consiguientes responsabiliclades que a cada uno correspondieran, en cuanto a la acción, el estilo de la obra y el vocabulario de la misma, diferentes en la obra original y la adaptación, en caso de serto.

En los tres actos de Los últimos romanos, sucesivamente se 
muestra el estado de ánimo y la actitud de Bruto, después del asesinato de César, y la situación de Roma en decadencia.

Hay en la tragedia versos vibrantes - que bien podían convenir a la situación de México en aquella época- como éstos:

...los magistrados

con insolencia vil rasgan las leyes,

y el crimen las insulta victorioso.

El oro compra al Pueblo y al Senado,

nombra tribunos, cónsules qüestores.

Mirad a la fatal hipocresía

con la patria en los labios, no en el pecho:

ved a la libertad entre facciones

agonizando triste, y del imperio

de mano en mano errar la espada impia...

En otro lugar dice:

He visto a la república entregada

a mil facciones, y anegada en sangre

por la insensata furia de sus hijos.

Culmina la tragedia con la decisión final de Porcia, que se hiere después de haber rehusado el perdón de los triunviros, en altiva respuesta:

Se perdona

sólo a los criminales,

Para replicar, orgullosamente, cuando Agripa le pregunta:

¿Contra tanto poder dónde ocultarte?

-En el infierno...

...Allí me esperan

Bruto, Marco y Catón.-Servid vosotros.

No es preciso insistir en analogías perceptibles, para afirmar que habia muchas semejanzas entre la Roma de la tragedia y el México de la realidad palpada por Heredia. (Recordemos que en mayo de 1826 él mismo habia escrito acerca del rumor de una 24 
invasión española). Si el poeta acertó a elegir una obra en que aquéllos existiesen o si puso toda su vehemencia de amigo del orden dentro de la libertad, para señalar ese parecido, la crítica lo dirá algún día, al examinar de cerca, detenidamente, como lo merece, la tragedia Los últimos romanos.

Aquí para cerrar este breve ensayo, sólo se desea señalar a la atención de quien la ponga en este aspecto de la obra herediana, el hecho de que la tragedia Los últimos romanos más bien parece, si no es una obra original, refundición o adaptación que traducción o imitación de una obra del teatro francés de aquella época; sobre todo, por la brevedad.

Llevada a escena, la duración de toda la tragedia, sin intermedios, apenas llegaría a poco más de una hora. Compárese, por ejemplo, Sila (75 páginas) con Los últimos romanos, tragedia impresa en 28 páginas, que se reducen a dos docenas de páginas, si se descuentan aquéllas en que están portada, dedicatoria y personajes.

La acción de Pirro, Atreo, Sila, Tiberio, Xicotencal o los tlascaltecas y dos de las proyectadas traducciones que González. del Valle incluye en el apéndice de su Cronología herediana, se hallaba distribuida en cinco actos; Abufar o la familia árabe tiene cuatro. Lo mismo que la tragedia inconclusa de la mocedad de Heredia - Motezuma o los mexicanos-y Cayo Graco, la tragedia Los últimos romanos, sólo tiene tres actos.

Sería oportuno comparar - no sólo por la extensión sino también por la forma - esta última tragedia, con las anteriores; subrayar la acentuada predilección que Heredia tenía -como alto poeta- por la tragedia, ya que sólo en contadas ocasiones afronta el drama en un acto o desciende hasta el sainete; pero todo ello alargaría en exceso estas páginas que sólo quieren ser la modesta contribución de un mexicano de hoy, en el homenaje rendido al cubano ilustre que hace ahora precisamente un siglo se extinguió en México: aquél México que lo acogió con sonrisas primero y le enseñó después la mueca de leproso de la anar- 
quía; aquél Méxiço del cual recibió gratos dones y duras enseñanzas; aquél México que amó, a pesar de sus defectos, que supo honrar, como hijo adoptivo libre de ambiciones materiales, y para el que buscó - a través del ejemplo de una tragedia- un remedio en sus convulsiones políticas.

Francisco Monterde, Universidad Nacional de México. 
